\title{
What proportion of primary psychiatric interventions are based on evidence from randomised controlled trials?
}

\author{
John R Geddes, David Game, Neil E Jenkins, Lorraine A Peterson, Gill R Pottinger, David \\ L Sackett
}

\begin{abstract}
Objectives-To estimate the proportion of psychiatric inpatients receiving primary interventions based on randomised controlled trials or systematic reviews of randomised controlled trials.

Design-Retrospective survey.

Setting-Acute adult general psychiatric ward.

Subjects-All patients admitted to the ward during a 28 day period.

Main outcome measures-Primary interventions were classified according to whether or not they were supported by evidence from randomised controlled trials or systematic reviews.

Results-The primary interventions received by $26 / 40 \quad(65 \% ; 95 \%$ confidence interval (95\% CI) $51 \%$ to $79 \%$ ) of patients admitted during the period were based on randomised trials or systematic reviews. Conclusions-When patients were used as the denominator, most primary interventions given in acute general psychiatry were based on experimental evidence. The evidence was difficult to locate; there is an urgent need for systematic reviews of randomised controlled trials in this area. (Quality in Health Care 1996;5:215-217)
\end{abstract}

Keywords: psychiatry, interventions, evidence and honorary consultant psychiatrist

David Game, medical student

Neil E Jenkins, medical student

Lorraine A Peterson, medical student

Gill R Pottinger, medical student

\section{National Health}

Service Research and Development

Programme Centre for

Evidence Based

Medicine, Nuffield

Department of

Medicine,

Oxford-Radcliffe NHS

Trust, Oxford

David L Sackett,

professor of clinical

epidemiology and

director

Correspondence to:

Dr John Geddes, University

Department of Psychiatry,

Warneford Hospital, Oxford

OX3 7JX.

Accepted for publication 14 August 1996 found that over $50 \%$ of patients received treatment based on evidence from randomised controlled trials. ${ }^{4}$ The proportion rose to over $80 \%$ when convincing non-experimental evidence was also included. This finding indicates that it may be possible both to develop guidelines based on evidence and estimate the quality of care by measuring the use of interventions of known effectiveness.

It could be argued that acute general medicine is one area of medicine in which the standard of evidence is unusually high and that their findings are unlikely to be able to be generalised to other specialities or to general practice. The only way of ascertaining this is to repeat their study in other branches of medicine. Gill et al have recently reported a study in general practice which found that $81 \%$ of interventions were based on randomised controlled studies or convincing nonexperimental evidence. ${ }^{5}$

We estimated the proportions of principle interventions, received by patients on a general psychiatric ward, which were based on randomised controlled trials or systematic reviews of randomised controlled trials.

\section{Methods}

The study sample consisted of all patients treated on one ward at the Warneford Hospital in Oxford between 28 May and 23 June 1995. Psychiatric services in Oxfordshire are sectorised, and the ward provided inpatient psychiatric services to a part of Oxford city centre. One consultant psychiatrist (JG) was responsible for the care of all but two patients included in the study, although treatment was often initiated by doctors who were not consultants. Although the medical staff were interested in medicine based on evidence and attempted to used therapeutic maneouvres which they thought to be effective, they were not aware of the specific evidence of effectiveness in most cases. The study was not planned until after the study period and so it was unlikely that awareness of being observed influenced behaviour. At the end of the period, all notes were gathered and the principal clinical diagnosis (that which seemed to be the patient's main reason for admission) was determined for each patient and coded according to the diagnostic guidelines of the 10th revision of the international classification of diseases (ICD-10). ${ }^{6}$ The primary intervention, which represented the most important attempt to cure or alleviate the primary diagnosis after admission, was identified.

A search was first performed with Medline (accessed by Silver Platter Information) for a 
Table 1 Primary diagnoses and therapeutic interventions based on randomised controlled trials

\begin{tabular}{|c|c|c|c|c|}
\hline Primary diagnoses & $\begin{array}{l}\text { Primary medical } \\
\text { intervention }\end{array}$ & $\begin{array}{l}\text { Patients } \\
\text { (n) }\end{array}$ & $\begin{array}{l}\text { Reference for } \\
\text { randomised } \\
\text { controlled trials } \\
\text { (systematic } \\
\text { review) }\end{array}$ & $\begin{array}{l}\text { Rating } \\
\text { of study }\end{array}$ \\
\hline $\begin{array}{l}\text { F10 Alcohol withdrawal } \\
\text { state }\end{array}$ & $\begin{array}{l}\text { Chlordiazepoxide } \\
\text { withdrawal regimen }\end{array}$ & 1 & 10 & B \\
\hline \multicolumn{5}{|l|}{ F20 Schizophrenia } \\
\hline \multirow{6}{*}{$\begin{array}{l}\text { Control of exacerbation } \\
\text { of psychotic symptoms }\end{array}$} & Chlorpromazine & 2 & $11(12)$ & B \\
\hline & Trifluoperazine & 4 & (12) 13 & A \\
\hline & Haloperidol & 1 & (12) & B \\
\hline & $\begin{array}{l}\text { Zuclopenthixol acetate } \\
\text { (intramuscular) }\end{array}$ & 1 & 14 & B \\
\hline & Sulpiride & 3 & (15) & B \\
\hline & Risperidone & 1 & 16 & B \\
\hline $\begin{array}{l}\text { Establishment of } \\
\text { prophylactic treatment }\end{array}$ & $\begin{array}{l}\text { Depot neuroleptic } \\
\text { treatment }\end{array}$ & 4 & 17 & B \\
\hline $\begin{array}{l}\text { F31 Prophylaxis for } \\
\text { bipolar affective disorder }\end{array}$ & Lithium carbonate & 2 & 18 & B \\
\hline \multirow{4}{*}{$\begin{array}{l}\text { F32/F33 Depressive } \\
\text { episode or disorder }\end{array}$} & Amitriptyline & 2 & 19 & A \\
\hline & Paroxetine & 1 & 20 & B \\
\hline & Moclobemide & 1 & 21 & B \\
\hline & $\begin{array}{l}\text { Lithium augmentation of } \\
\text { antidepressant resistant } \\
\text { disorder }\end{array}$ & 3 & $22(23)$ & B \\
\hline Total & & $26(65 \%)$ & & \\
\hline
\end{tabular}

* According to classification of the description of randomisation in the Cochrane collaboration handbook.

systematic review of randomised controlled trials of the effectiveness of the specific treatment used in each condition. If a systematic review was not found, a randomised controlled trial was searched for. If several appropriate randomised controlled trials were found, we used the one which was most appropriate for the clinical situation. For example, for antidepressants, we chose a study performed in an inpatient setting rather than in primary care. Very small randomised controlled trials comparing two active treatments were not used because of the high likelihood of a type II error. For treatments introduced before 1966, hand searches of the British fournal of Psychiatry, American fournal of Psychiatry, fournal of Mental Science, fournal of Nervous and Mental Disease, and Archives of General Psychiatry were also performed. We used published guides to critically appraise randomised controlled trials and systematic reviews. ${ }^{78}$ Randomised controlled trials were graded according to the guidelines of the Cochrane collaboration, which classes studies

Table 2 Primary interventions not based on experimental evidence

\begin{tabular}{|c|c|c|}
\hline Primary diagnosis (ICD-10) & Primary medical intervention & Patients (n) \\
\hline F10 Withdrawal state & Chlordiazepoxide and thioridazine & 1 \\
\hline \multirow[t]{2}{*}{ F25 Schizoaffective psychosis } & $\begin{array}{l}\text { Increase amitriptyline to } 150 \mathrm{mg} \text { (already } \\
\text { on several other drugs) }\end{array}$ & 1 \\
\hline & Lithium carbonate and thioridazine & 1 \\
\hline \multirow[t]{3}{*}{$\begin{array}{l}\text { F31 Bipolar affective disorder (acute } \\
\text { manic relapse) }\end{array}$} & $\begin{array}{l}\text { Lorazepam and sulpiride (refused } \\
\text { lithium) }\end{array}$ & 1 \\
\hline & Lithium carbonate and chlorpromazine & 2 \\
\hline & Lithium carbonate and droperidol & 1 \\
\hline $\begin{array}{l}\text { F33 Recurrent depressive disorder } \\
\text { with psychotic symptoms }\end{array}$ & Trifluoperazine and fluoxetine & 1 \\
\hline $\begin{array}{l}\text { F38.10 Recurrent brief depressive } \\
\text { disorder }\end{array}$ & Antidepressant stopped & 1 \\
\hline F43 Acute stress reaction & General supportive care & 1 \\
\hline $\begin{array}{l}\text { F60.3 Emotionally unstable } \\
\text { personality disorder }\end{array}$ & General supportive care & 2 \\
\hline $\begin{array}{l}\text { F68.1 Factitious disorder } \\
\text { (Munchausen's syndrome) }\end{array}$ & Zuclopenthixol acetate (intramuscular) & 1 \\
\hline Unknown & Observation - patient absconded & 1 \\
\hline Total & & $14(35 \%)$ \\
\hline
\end{tabular}

according to the description of the randomisation procedure. This has been found to correlate with the quality of the study. ${ }^{9}$ Three grades of randomisation were discriminated, ranging from A (adequate), if there was a description of independent random allocation, to $C$ (inadequate), if allocation may have been influenced by the clinician or was non-random.

On the basis of the evidence, each primary intervention was classified into one of two groups: (a) intervention based on evidence from randomised controlled trials or systematic reviews of randomised controlled trials; $(b)$ interventions without evidence from randomised controlled trials. This included drug regimens based on pathophysiological principles rather than randomised controlled trials, and combinations of drugs which had not been subjected to randomised controlled trials

The primary intervention was considered to be that actually received by the patient - some patients chose not to accept the intervention of choice. We purposely restricted the interventions we considered to specific interventions such as drugs, electroconvulsive therapy, or specific forms of psychotherapy rather than interventions involving service organisation, such as admission to hospital.

\section{Results}

During the 28 day period, a total of 43 patients were treated on the 24 bed ward. Three patients were transferred to other wards before definitive treatment was started. These patients were excluded from the study. Twenty six of the remaining 40 patients $(65 \% ; 95 \%$ confidence interval ( $95 \%$ CI) $51 \%$ to $79 \%$ ) received primary interventions which were based on evidence from randomised controlled trials or overviews (table 1 ). When a systematic review and a randomised controlled trial which particularly suited the clinical problem were located, both were cited. Table 2 shows the primary interventions not based on experimental evidence. Of these, one patient refused the preferred treatment (which would have been based on evidence from a randomised controlled trial) and five subjects received combinations of drugs which have not, so far as we could tell, been evaluated in randomised controlled trials although they seemed to be widely used in clinical practice. ${ }^{24}$ One patient, in whom a firm diagnosis of Munchausen's syndrome was subsequently made, received an emergency intramuscular injection for disturbed behaviour and simulated psychotic symptoms (which would have been based on evidence if the psychotic symptoms had been genuine).

\section{Discussion}

In $65 \%$ of the psychiatric patients who were treated on the ward during the 28 day period the primary medical intervention was based on a randomised controlled trial or a systematic review of randomised controlled trials. This proportion is not significantly higher than that reported in general medicine $\left(53 \%, \chi^{2} 1.65, \mathrm{df}\right.$ $1, \mathrm{P}=0.20$ ) with a similar study protocol. ${ }^{4}$ 
Although the design of our study was similar to that used by Ellis et al, one notable difference was that it was performed retrospectively at the end of the month and so was less likely to be susceptible to a Hawthorne effect. However, the consultant was aware of the study by Ellis et $a l$ and it remains possible that his management decisions were influenced by this knowledge, although he did not make all the treatment decisions. Even if the findings cannot be generalised to other psychiatric units, they still imply that most primary medical interventions in psychiatric inpatients can be based on evidence. Indeed, as no prospective attempt was made to maximise the proportion of interventions based on evidence, it is likely that an even higher proportion is potentially achievable. It is also possible that we failed to find existing evidence for some interventions.

In interpreting our findings, it is important to bear in mind that psychiatry is a multidisciplinary specialty and that other interventions made by the medical and nursing staff or by the occupational therapists and psychologists are likely to be related to the quality of care. It is probable that the proportion of interventions which are based on evidence would have fallen if we had included every intervention.

It may be argued that the proportion was high because most of the primary medical interventions were pharmacological, and randomised controlled trials are required by the licensing authorities. Furthermore, perhaps admission to hospital was the primary medical intervention for every patient. We do not consider that these points alter the main conclusion of the study - that is, with patients as the denominator, most primary medical interventions given to psychiatric inpatients are based on evidence.

However, we cannot conclude that there is systematically reviewed and readily available evidence for most psychiatric interventions. The evidence was difficult to find and we only found two usable systematic reviews of randomised controlled trials. Furthermore, several different drugs were used in specific disorders - for example, schizophrenia and depression - because there is a lack of good evidence on the comparative efficacies or cost effectiveness of treatments in psychiatry. ${ }^{25}$ Many randomised controlled trials of psychotropic drugs are aimed at showing that new compounds are as effective as older drugs, but with reduced side effects. It is likely that, if more systematic reviews were available, our estimate of the proportion of interventions which were based on evidence would change. There was very little experimental evidence for the interventions in patients who did not have schizophrenia or affective disorders. In general, the commonest interventions in the most often diagnosed disorders were the best evaluated.

Our study was small and based on one inpatient ward. We do not know whether our findings could be generalised, and it would be useful to undertake surveys of the proportion of mental health interventions which are based on sound evidence in other settings. There is also an urgent need for systematic reviews of the randomised controlled trials (published and unpublished) which have been undertaken. These should not be restricted to primary psychiatric interventions, but need to include other interventions which are potentially clinically effective. Systematic reviews are required before developing guidelines based on evidence and before adherence to interventions of known effectiveness is used as a measure of the quality of psychiatric inpatient care.

1 Implementing clinical practice guidelines: can guidelines be used to improve clinical practice. Effective Health Care 1994;1:8.

2 Mant J, Hicks N. Detecting differences in quality of care: the sensitivity of measures of process and outcome in treating acute myocardial infarction. BMf 1995;311:793-6.

3 Smith R. Where is the wisdom? The poverty of medical evidence. $B M 7$ 1991;303:798-9.

4 Ellis J, Mulligan I, Rowe J, Sackett DL. In-patient general medicine is evidence-based. Lancet 1995;346:407-10.

5 Gill P, Dowell AC, Neal RD, Smith N, Heywood P, Wilson AK. Evidence based general practice: a retrospective study of interventions in one training practice. BMF 1996 312:819-21.

6 World Health Organisation. International classification of diseases, 10th ed. Geneva: WHO, 1992.

7 Guyatt GH, Sackett DL, Cook DJ. User's guides to the medical literature. II How to use an article about therapy or prevention $\mathrm{A}$. Are the results of the study valid? $f A M A$ or prevention A. A

8 Laupacis A, Wells G, Richardson S, Tugwell P. User's guides to the medical literature. VI. How to use an overview fAMA 1994;272:1367-71.

9 Sackett DL, Oxman AD. The Cochrane collaboration handbook . Oxford: Cochrane Collaboration, 1994.

10 Kaim SC, Klett CJ, Rothfield B. Treatment of the acute alcohol withdrawal state: a comparison of four drugs. $\mathrm{Am}$ f Psychiatry 1969;125:1640-6.

11 Kurland AA, Hanlon TE, Totom MH, Ota KY, Simopoulos AM. The comparative effectiveness of six phenothiazine compounds, phenobarbital and inert placebo in the treatcompounds, phenobarbital and inert placebo in the treat-
ment of acutely ill patients: global measures of severity of ment of acutely ill patients: global meas
illness. $\mathcal{F}$ Nerv Ment Dis 1961;133:1-18.

12 Quality assurance project. Treatment outlines for the management of schizophrenia. Aust $N Z \mathcal{F}$ Psychiatry 1984;18:19-38.

13 Hamilton M, Hordern A, Waldrop FN, Lofft J. A controlled trial on the value of prochlorperazine, trifluoperazine and intensive group treatment. Br f Psychiatry 109:510-22.

14 Baastrup PC, Alhfors UG, Bjerkenstedt L, Dencker SJ Fensbo C, Gravem A, et al. A controlled Nordic multicentre study of zuclopenthixol acetate in oil solution, haloperidol and zuclopenthixol in the treatment of acute psychosis. Acta Psychiatr Scand 1993;87:48-58.

15 Caley CF, Weber SS. Sulpiride: an antipsychotic with selective dopaminergic antagonist properties. Ann Pharmacother 1995;29:152-60.

16 Marder SR, Meibach RC. Risperidone in the treatment of schizophrenia Am f Psychiatry 1994;151:825-35.

17 Jolley AG, Hirsch SR, Morrison E, McRink A, Wilson L. Trial of brief intermittent neuroleptic prophylaxis for selected schizophrenic outpatients: clinical and social outcome at two years. BMF 1990;301:837-42.

18 Prien RF, Caffey EM, Klett CJ. Prophylactic efficacy of lithium carbonate in manic-depressive illness. Report of the Veterans Administration and National Institute of Mental Health Study Group. Arch Gen Psychiatry 1973 28:337-41.

19 Burt CG, Gordon WF, Holt NF, Hordern NF. Amitriptyline in depressive states: a controlled trial. fournal of Mental Science 1962;108:711-30.

20 Stuppaeck CH, Geretsegger C, Whitworth AB, Schubert $H$ Platz T, Konig P, et al. A multicenter double-blind trial of paroxetine versus amitriptyline in depressed inpatients. $\mathcal{F}$ Clin Psychopharmacol 1994;14:241-6.

21 Guelfi JD, Payan C, Fermanian J, Pedarriosse A-M, Manfredi R. Moclobemide versus clomipramine in endog enous depression: a double blind randomised controlled trial. Br f Psychiatry 1992;160:519-24.

22 Katona CLE, Abou-Saleh MT, Harrison DA, Nairac BA Edwards DRL, Lock T, et al. Placebo-controlled trial of lithium augmentation of fluoxetine and lofepramine. $B r f$ Psychiatry 1995;166:80-6.

23 Austin MP, Souza FG, Goodwin GM. Lithium augmentaAustin MP, Souza FG, Goodwin GM. Lithium augmentation in antidepressant-resistant patients.
analysis. $B r \mathcal{F}$ Psychiatry 1991;159:510-4.

24 Paykel E, ed. Handbook of affective disorders. Edinburgh Churchill Livingstone, 1992.

25 Johnson AL. Clinical trials in psychiatry. Psychol Med 1983 13:1-8. 